\title{
Calidad higiénica y sanitaria de leche cruda acopiada en diferentes regiones colombianas
}

\author{
The hygienic and sanitary quality of raw milk collected \\ fromdifferent regions in Colombia
}

\section{Qualidade higiênica e sanitária do leite cru coletado em diferentes regiões da Colômbia}

\author{
Juan F. Vásquez' ${ }^{1}$ Erica T. Loaiza², Martha Olivera' ${ }^{1}$
}

\footnotetext{
1 MV, MSc Universidad de Antioquia, Facultad de Ciencias Agrarias. Grupo de Investigación Biogénesis. Medellín Colombia. Cooperativa Colanta Ltda.

2 MV, Dr.Sc Agr. Universidad Pontificia Bolivariana Medellín, Escuela de Ciencias de la Salud. Email: jufevaca@gmail.com
}

Recibido: diciembre 29 de 2011. Aceptado: agosto 28 de 2012

\begin{abstract}
Resumen
Se analizaron los resultados de pruebas para calidad higiénica y sanitaria de 705.210 .165 litros de leche cruda acopiados por una empresa de lácteos colombiana durante 2010. Esta fue enviada desde 3.939 tanques de enfriamiento a 11 plantas de acopio localizadas en Antioquia, Sabana de Bogotá, Magdalena Medio, Viejo Caldas y Costa Atlántica. Mediante un ANAVA no paramétrico de Kruskal Wallis se encontraron diferencias significativas entre plantas ( $\mathrm{P}<0.01)$ para los promedios de Recuento de Células Somáticas/ml (RCS) y Unidades Formadoras de Colonia/ml (UFC). Las plantas con menores promedios de recuentos de UFC/ml fueron Funza (19.000), Armenia (63.000) y San Pedro (68.000). Los menores RCS/ml se encontraron en Puerto Boyacá (354.000), Funza (364.000) y Planeta Rica (373.000). El 93.90\% y 84.49\% de la leche muestreada supera los estándares de calidad en recuentos de UFC para las legislaciones nacionales e internacionales, respectivamente. Para el estándar internacional de RCS, el 39.54\% de la leche muestreada presentó cumplimiento. No hubo variaciones significativas en los valores de UFC y RCS por efecto de la época del año y se encontró bajo nivel de asociación entre los valores de ambos parámetros $(r 2=0.43)$. El conocimiento de las falencias de calidad en cada cuenca lechera permitirá direccionar eficientemente los programas de extensión y mejoramiento de la calidad de la leche en las fincas según sus necesidades particulares.
\end{abstract}

Palabras claves: mastitis, normatividad, recuento de células somáticas, unidades formadoras de colonia

\begin{abstract}
The results of hygienic and sanitary quality tests on 705,210,165 litres of raw milk collected by a Colombian dairy company in 2010 were analysed. This milk was sent from 3,939 cooling tanks in11 storage centreson the savannah around Bogotá, the Middle Magdalena Valley, the Viejo Caldas region, the Antioquia department and on the Atlantic coast. Significant differences $(p<0.01)$ were found between plants for average colony forming units (CFU) and somatic cell count(SCC)using non parametric Kruskal Wallis one-way analysis of variance (ANOVA). The Funza (19,000), Armenia (63,000) and San Pedro $(68,000)$ storage centres had lower average CFU/ml counts whilst the Puerto Boyaca $(354,000)$, Funza $(364,000)$ and Planeta Rica centres (373,000)had lower SCC/ml. 93.90\% of the milk samples exceeded national CFU count standards and
\end{abstract}


$84.49 \%$ of them the pertinent international standards. $39.54 \%$ of the milk sampled complied with Regulated Control Scheme (RCS) international standards. No significant differences were found in CFU and SCC values due to the time of year and a low level of association was found between the values for both parameters $\left(r^{2}=0.43\right)$. Ascertaining limitations regarding milk quality standards /failure to comply with the min each Colombian dairy region will help to orientate further education programmes for farmers according to their particular needs and thereby lead to improving Colombian milk quality.

Keywords: colony forming unit, compliance percentage, mastitis, milk regulation, somatic cell count.

\section{Resumo}

Foram analisados os resultados dos testes de qualidade higiênico-sanitária de 705.210 .165 litros de leite cru coletado por uma empresa de laticínios da Colômbia em 2010. Este leite foi enviada de 3939 tanques de resfriamento de 11 instalações de armazenamento localizado no Sabana de Bogotá, Magdalena Medio, Viejo Caldas, Antioquia e Costa Atlântica. Diferenças significativas $(\mathrm{P}<0.01)$ para a média do UFC e CCS entre plantas usando uma ANOVA não paramétrico Kruskal Wallis. Plantas com menores médias de contagens de UFC/ml foram Funza (19.000), Armenia (63.000) e San Pedro (68.000). Menores CCS/ml foram encontrados em Puerto Boyacá (354.000), Funza (364.000) e Planeta Rica (373.000). Os 93.90\% e $84.49 \%$ das amostras de leite exceder os padrões de qualidade da contagem de UFC por nacionais e internacionais, respectivamente. Para o padrão de CCS internacional, a adesão foi 39,54\% do leite da amostra. Não foram encontradas diferenças significativas no UFC e CCS valores devidos à época do ano ( $\mathrm{P}=0.995$ e 0.996, respectivamente) e encontrou baixo nível de associação entre os valores dos dois parâmetros $(r 2=0.431)$. O conhecimento das falhas de qualidade em cada bacia leiteira vai abordar efetivamente o alcance e melhorar a qualidade do leite nas fazendas de acordo com suas necessidades.

Palavras chave: a laite regulação, a porcentagem de adesão, contagem de células somáticas, mastite, unidades formadoras de colônias

\section{Introducción}

En vista de la firma de los tratados de libre comercio con Europa, Canadá y Estados Unidos es importante conocer cuál es la calidad de la leche que se produce en Colombia. Ferraro (2006), define leche de calidad a la proveniente del ordeño de vacas sanas bien alimentadas, con cantidad y calidad apropiada de componentes sólidos (grasa, proteína, lactosa, vitaminas y minerales), libre de olores, sedimentos, sustancias extrañas, residuos químicos e inhibidores, libre de bacterias causantes de enfermedad, y con un mínimo de carga microbiana y células somáticas. Las bacterias en leche cruda pueden afectar la calidad, seguridad y aceptación del consumidor de productos lácteos. En salud pública, su presencia puede dar lugar a enfermedades zoonóticas a través de infecciones por Listeria monocytogenes, Salmonella spp., Staphylococcus aureus, Campylobacter jejuni y Mycobacterium tuberculosis como lo expresaron Jayarao et al., (2006). Además, los altos recuentos de bacterias en leche cruda además son responsables por defectos en la calidad de la leche pasteurizada, UHT, leche en polvo, mantequilla y quesos (Barbano et al., 2006). Por otro lado, los altos recuentos de células somáticas (RCS) en leche cruda incrementan la actividad enzimática lipolítica y proteolítica, lo cual afecta las características sensoriales de la leche con sabores rancios o picantes en la misma según Ma et al., (2000), al tiempo que afectan la calidad de la caseína y por tanto, el rendimiento quesero de acuerdo a lo encontrado por Norman et al. (2000). En contraste, bajos RCS han sido relacionados con mayor producción lechera y mejor calidad de derivados lácteos. En los hatos, el monitoreo del RCS ha sido un indicador del nivel de control de mastitis y salud de la ubre. Debido a la importancia de la calidad de la leche, muchos países tienen legislaciones para asegurar la calidad y seguridad del producto final. La Tabla 1 presenta los estándares de calidad higiénica y sanitaria para leche cruda de diferentes regiones del mundo.

\section{Materiales y métodos}

\section{Tipo de estudio}

El estudio de tipo retrospectivo se realizó a través de los resultados obtenidos en la leche analizada por los laboratorios de control de calidad de una empresa de lácteos colombiana en 11 centros de acopio localizados en regiones bajo sistemas de producción de trópico alto en las plantas de: Funza (que cubre la Sabana de Bogotá); San Pedro, Santa Rosa y Yarumal (que cubren el altiplano norte antioqueño); trópico medio: Armenia (que acopia leche del Viejo Caldas y norte del departamento del Valle); Medellín y Frontino (que cubren el centro y occidente de Antioquia, respectivamente) y de trópico bajo: Puerto Boyacá (que cubre Magdalena Medio); y Barranquilla, San Onofre y Planeta Rica (que acopian en la Costa Atlántica) (Fig. 1). La tabla 2 muestra el volumen de leche captado 
Tabla 1. Estándares de calidad higiénica y sanitaria de leche cruda en diferentes países en el mundo

\begin{tabular}{|c|c|c|c|}
\hline País & $\begin{array}{l}\text { Tipo de } \\
\text { calidad }\end{array}$ & Máximo valor permitido & Fuente \\
\hline Colombia & Higiénica & 175.000-200.000 UFC/ml según región. & Ministerio de Agricultura 2012 \\
\hline \multirow{3}{*}{ Australia } & Higiénica & 100.000 UFC/ml. & \multirow{3}{*}{ Norman et al., 2000} \\
\hline & & & \\
\hline & Sanitaria & $400.000 \mathrm{CS} / \mathrm{ml}$ & \\
\hline Canadá & Sanitaria & $500.000 \mathrm{CS} / \mathrm{ml}$ & Elmoslemany et al., 2009 \\
\hline \multirow{2}{*}{ Estados Unidos } & Higiénica & 100.000 UFC/ml. & \multirow{2}{*}{ FDA, 2007} \\
\hline & Sanitaria & $750.000 \mathrm{CS} / \mathrm{ml}$ & \\
\hline Noruega & Sanitaria & $400.000 \mathrm{CS} / \mathrm{ml}$ & Norman et al., 2000 \\
\hline Nueva Zelanda & Sanitaria & $400.000 \mathrm{CS} / \mathrm{ml}$ & Norman et al., 2000 \\
\hline Suiza & Sanitaria & $400.000 \mathrm{CS} / \mathrm{ml}$ & Norman et al., 2000 \\
\hline \multirow{2}{*}{ Unión Europea } & Higiénica & 100.000 UFC/ml. & \multirow{2}{*}{$\begin{array}{l}\text { Van Schaik et al., } 2002 \\
\text { McLaughlin } 2006\end{array}$} \\
\hline & Sanitaria & 400.000 CS/ml. & \\
\hline
\end{tabular}

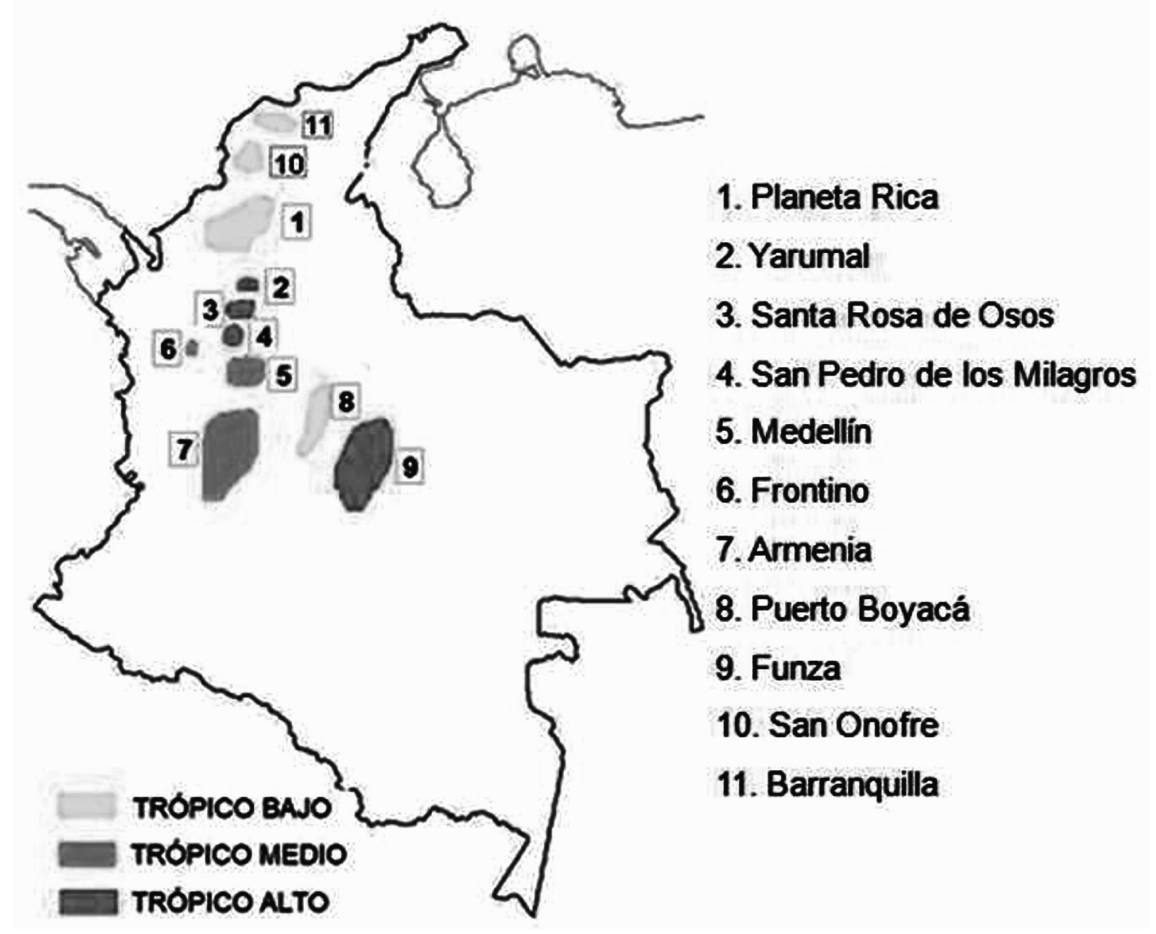

Figura 1. Áreas de influencia de los centros de acopio de leche en estudio y su ecosistema predominante. 
Tabla 2. Leche captada en las diferentes regiones colombianas durante 2010

\begin{tabular}{l|l|c}
\hline \multicolumn{1}{c|}{ Zona de producción } & \multicolumn{1}{|c}{ Planta } & Litros de leche captada \\
\hline \multirow{2}{*}{ Trópico alto (>2000 msnm) } & Funza & 81.060 .043 \\
& Yarumal & 47.169 .383 \\
& Santa Rosa & 113.714 .523 \\
& San Pedro & 282.190 .819 \\
Trópico medio $(500-2000$ msnm) & Armenia & 26.642 .296 \\
& Frontino & 12.477 .941 \\
Trópico bajo $(<500$ msnm) & Medellín & 112.955 .796 \\
& Puerto Boyacá & 6.315 .676 \\
& Planeta Rica & 46.130 .167 \\
& Barranquilla & 5.533 .013 \\
& San Onofre & 4.478 .115 \\
& & 738.667 .771 \\
\hline
\end{tabular}

por cada centro de acopio. La información no permite definir cuantos litros de leche provienen de cada uno de los diferentes tipos de producción (especializado o doble propósito).

\section{Recuento de Células Somáticas y Unidades Formadoras de Colonia}

La medición de UFC y RCS fue realizada por la lactoindustria mediante tecnología de citometría de flujo (bactoscan, fossomatic, y combifoss; FOSS Inc ${ }^{\circledR}$ ); los cuales están validados con las metodologías internacionales de referencia AOAC 986.33 para medición de bacterias mesófilas aerobias en leche y la ISO 133661:2008 (IDF 148-1: 2008) para células somáticas.

\section{Análisis de la información - Diseño estadístico}

Basados en el informe consolidado de la lactoindustria que contenía mes a mes el promedio ponderado por volumen de UFC y RCS para cada planta, se calcularon los rangos de calidad y el porcentaje de leche que cumple con los estándares de calidad nacional e internacional en los diferentes centros de acopio.

Para evaluar diferencias de RCS y UFC entre plantas, se realizó un ANAVA no paramétrico de Kruskal Wallis. Se optó por este análisis debido a que no pudieron ser validados los supuestos de normalidad de los datos mediante los estadísticos de Shapiro - Wilk. El efecto del mes sobre los niveles de UFC y RCS se determinó mediante un diseño completamente aleatorizado. El grado de asociación entre UFC y RCS a lo largo del año se determinó mediante un análisis de regresión lineal simple no paramétrica, obteniendo niveles de significancia y valor de r2 no significativos. Se consideró como significativo un valor de $\mathrm{P}<0.05$. Dichas pruebas fueron procesadas a través del programa estadístico SPSS $^{\circledR}$ versión 17.0.

\section{Resultados}

En Colombia, Suárez y Bazzani (2010), estimaron que la producción de leche durante 2009 fue de 5.760 millones de litros. En este estudio se analizaron los resultados provenientes de 705.210.295 litros de leche refrigerada (es decir, $12.24 \%$ de la producción nacional), procedentes de 3.939 tanques de enfriamiento de leche en los que depositaban leche 7.090 productores.

Los resultados del promedio ponderado de recuento de UFC por planta se encuentran en la Tabla 3, al igual que el porcentaje de leche que cumple con los parámetros de la más reciente resolución de pago por calidad de leche, Resolución 0017 Ministerio de Agri- 
Tabla 3. Calidad higiénica de leche cruda en tanques y porcentaje del volumen que cumple estándares nacionales en 11 regiones colombianas.

\begin{tabular}{|c|c|c|}
\hline Planta & $\begin{array}{c}\text { Promedio } \\
(\text { UFC } / \mathrm{ml} \times 1000)^{*}\end{array}$ & $\begin{array}{l}\text { (\%) del volumen acopiado que cumple } \\
\text { la norma nacional }{ }^{* *}\end{array}$ \\
\hline Funza & 19 & 99.2 \\
\hline Armenia & 63 & 96.8 \\
\hline San Pedro & 68 & 95.7 \\
\hline San Onofre & 72 & 97.5 \\
\hline Frontino & 74 & 87.7 \\
\hline Santa Rosa & 81 & 94.5 \\
\hline Yarumal & 82 & 94.5 \\
\hline Pto. Boyacá & 90 & 83.6 \\
\hline Planeta Rica & 104 & 75.9 \\
\hline Medellín & 122 & 91.8 \\
\hline Barranquilla & 233 & 7.48 \\
\hline Promedio general & 82 & 93.9 \\
\hline
\end{tabular}

cultura (2012). Para este efecto, se consideró leche bajo cumplimiento como el porcentaje del volumen de la leche enviada con recuento inferior a 200.000 UFC/ml. El análisis de varianza presenta diferencias estadísticamente significativas $(\mathrm{P}<0.01)$ en al menos una de las plantas para el promedio de UFC, sin embargo, no se pudo establecer específicamente entre cuales plantas, dado que la prueba no paramétrica utilizada no permite realizar comparaciones entre grupos.

Adicional a los promedios de recuento de UFC por planta, se realizó una distribución de los recuentos por rangos con el fin verificar cuánta leche presenta cumplimiento de normas mucho más estrictas, como las europeas y las norteamericanas. Los resultados encontrados se encuentran consignados en la Tabla 4.

El 93.90\% de la leche refrigerada cumplió con el estándar de máximo 200.000 UFC/ml que exige la Resolución 017 de 2012. El 84.49\% de la leche refrigerada cumplió con las normas internacionales exigidas por la Comunidad Europea y Estados Unidos para leche cruda (máximo $100.000 \mathrm{UFC} / \mathrm{ml}$ ), y un $47.53 \%$ de la leche se encontró en el rango de UFC más bajo (menor de $25.000 \mathrm{UFC} / \mathrm{ml}$ ), lo que clasificaría esta leche cruda como de muy alta calidad bacteriológica.
En lo que respecta a la calidad sanitaria de la leche, la Tabla 5 ilustra los promedios de RCS por plantas y el porcentaje de leche que cumple los estándares de la Comunidad Europea. No se tomó un estándar nacional de células somáticas debido a que no existe en la legislación colombiana. Para el Decreto 616 de 2006 y la Resolución 017 de 2012, las bonificaciones de RCS son voluntarias y discrecionales de las empresas que deseen mejorar este aspecto de la calidad de la leche.

Los niveles de células somáticas de la leche analizada fueron altos en general. En promedio, solo las plantas de Puerto Boyacá, Funza, Planeta Rica y Barranquilla cumplieron la norma. El análisis estadístico presentó diferencias significativas $(\mathrm{P}<0.01)$ para el promedio de RCS entre las plantas analizadas. Con base en el volumen total de leche, el promedio de células somáticas fue de $642.000 \mathrm{CS} / \mathrm{ml}$, recuento superior al de los niveles deseables de RCS de 400.000 como máximo. Analizando la distribución del volumen de leche por rangos se puede tener mejores elementos de análisis. La Tabla 6 ilustra la distribución del volumen de leche por rangos de RCS.

El $41.82 \%$ de la leche en tanques cumplió con los estándares de la Comunidad Europea para RCS. Los 
Tabla 4. Calidad higiénica de la leche cruda discriminada por rangos durante 2010.

\begin{tabular}{c|c|c}
\hline Rangos (UFC) & \multicolumn{1}{|c|}{ Litros } & Volumen (\%) \\
\hline Menos de 25.000 & 335.196 .574 & 47.5 \\
$25.001-50.000$ & 138.268 .199 & 19.6 \\
$50.001-100.000$ & 122.325 .694 & 17.4 \\
$100.001-150.000$ & 39.748 .244 & 5.6 \\
$150.001-200.000$ & 20.471 .835 & 2.9 \\
$200.001-225.000$ & 6.166 .295 & 0.87 \\
$225.001-325.000$ & 20.798 .718 & 2.95 \\
$325.001-425.000$ & 8.814 .650 & 1.25 \\
$425.001-525.000$ & 4.164 .355 & 0.59 \\
$525.001-625.000$ & 1.612 .757 & 0.23 \\
Mayor a 625.001 & 7.642 .846 & 1.08 \\
Total & 705.210 .165 & 100 \\
\hline
\end{tabular}

estándares norteamericanos, tanto de Estados Unidos, como los de Canadá, son más flexibles (750.000 CS/ $\mathrm{ml}$ para el primero y $500.000 \mathrm{CS} / \mathrm{ml}$ para el segundo); el $76.76 \%$ de la leche del estudio está por debajo de $800.000 \mathrm{CS} / \mathrm{ml}$.

La Figura 2 ilustra el efecto del mes sobre el promedio ponderado de UFC y RCS durante 2010 para todas las plantas de acopio. En general los recuentos de UFC oscilaron entre 70.000 y $93.000 \mathrm{UFC} / \mathrm{ml}$, siendo más altos en los meses de noviembre, julio y agosto, y los más bajos febrero, marzo y abril. Los recuentos de células somáticas variaron entre 586.000 y 676.000 CS/ $\mathrm{ml}$, siendo mayores en enero, febrero y abril y más bajos en septiembre, octubre y noviembre. No se presentaron diferencias estadísticamente significativas en los valores de UFC y RCS entre los meses analizados (para las variaciones mensuales de UFC el valor de $p=0.995$ y para las de RCS $p=0.996$ ). Tampoco se encontró asociación significativa entre los niveles de RCS y el UFC a lo largo del año. El valor de $r^{2}$ fue de 0.43 con un valor de $p<0.01$

\section{Discusión}

Con respecto al análisis de las UFC, la planta de menor promedio ponderado fue Funza, seguida de Armenia y San Pedro donde se captan la leche de las zonas de lechería especializada más intensivas de Colombia.
Las plantas con menores porcentajes de leche que cumple los estándares de la norma son: Barranquilla, cuyas temperaturas máximas oscilan entre $22.6^{\circ} \mathrm{C}$ y $33.3^{\circ} \mathrm{C}$, con humedad relativa entre $77 \%$ y el $82 \%$ y Planeta Rica con temperatura media de $28^{\circ} \mathrm{C}$. Estas temperaturas, sumadas al tiempo existente entre el desplazamiento del producto desde los corrales de ordeño, hasta el tanque de enfriamiento pueden afectar las UFC tal como lo demostraron Posada et al., (2010) y Reyes et al., (2010). La planta de Medellín también presentó una menor calidad bacteriológica. Comparando los parámetros del estudio con los encontrados en la literatura a nivel nacional, los promedios de UFC de este trabajo fueron mucho menores a los encontrados por Calderón et al., (2006) y Piñeros et al., (2005) en Cundinamarca y Boyacá, respectivamente. (1.179.000 y 175.000 UFC vs 82.000 UFC del actual trabajo). Durante los últimos años se ha presentado una mejora contínua el los parámetros de UFC. Entre 2008 y 2010, el promedio de nacional de UFC en tanque de las plantas en estudio pasó de 141.000 a 93.000 y finalmente a $82.000 \mathrm{UFC} / \mathrm{ml}$ (datos sin publicar). Los resultados de este estudio no son extrapolables al resto de la leche del país, ya que del total de la producción nacional solo el $45.39 \%$ es captado por plantas de procesamiento según Suárez y Bazzani (2010), con exigencias variables según la empresa acopiadora y el resto del 


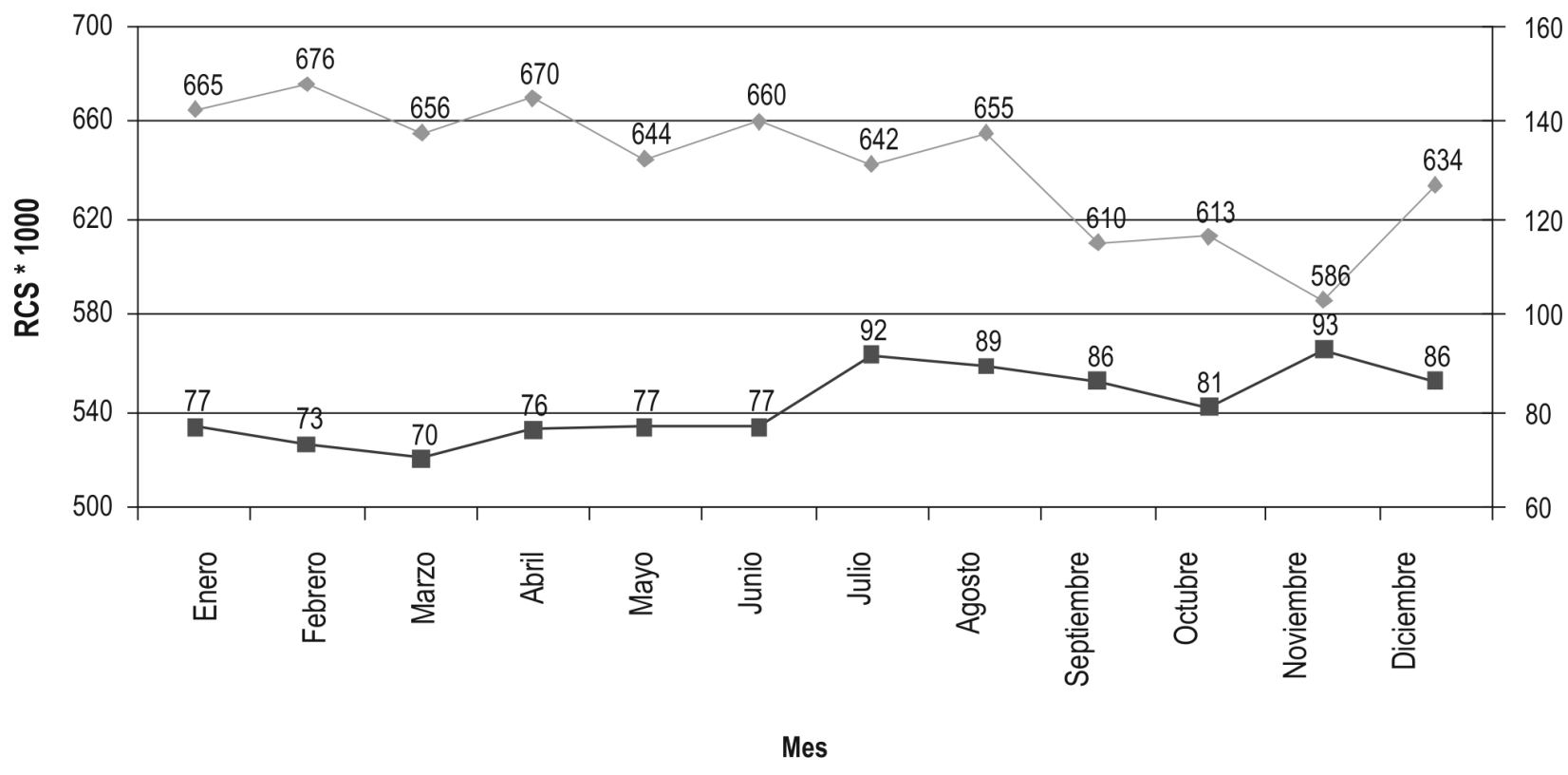
(i)

:

Figura 2. Estacionalidad en el recuento de UFC y RCS en tanque durante 2010 en leche cruda colombiana*

* Se presentó bajo nivel de asociación entre los niveles de UFC y RCS a lo largo del año ( $2=0.43, p<0.01)$. No se encontraron diferencias entre los niveles de UFC y RCS por efecto del mes.

país comercializa leche cruda o derivados lácteos de manera artesanal, con mínimos controles a la calidad.

La Tabla 4 muestra que casi la mitad de la leche acopiada $(47.53 \%)$ se encuentra en el rango de menos de $25.000 \mathrm{UFC} / \mathrm{ml}$; y el $93.90 \%$ de la leche cumple con el estándar de máximo 200.000 UFC/ml que exige la Resolución 017 de 2012 del Ministerio de Agricultura y Desarrollo Rural. El $84.49 \%$ cumple con las normas exigidas por la Comunidad Europea y Estados Unidos para leche cruda (máximo 100.000 UFC/ ml) McLaughlin (2006); FDA (2007). Sin embargo, el porcentaje de leche con recuentos superiores a las $100.000 \mathrm{UFC} / \mathrm{ml}$ sigue siendo alto (15.51\%) comparado con lo encontrado por Boor et al., (1988) en Estados Unidos, donde solo el 5.5\% de los productores de leche excedieron el estándar de 100.000 UFC/ml. En general, los estudios de calidad higiénica en Estados Unidos y Canadá, han reportado bajos recuentos que oscilaron entre 4 y $25 \mathrm{mil}$ UFC/ml según el estudio (Peeler et al., 1989; Elmoslemany et al., 2009 y Pantoja et al., 2009).

Respecto a la situación de los RCS los mejores promedios ponderados se encontraron en las plantas de Puerto Boyacá (354.000), Funza (364.000) y Planeta Rica $(373.000 \mathrm{CS} / \mathrm{ml})$. Puerto Boyacá y Planeta Rica son zonas de trópico bajo, donde predominan los sistemas de doble propósito. No hay estudios comparativos de este tipo de sistema en donde se muestre la salud de la ubre, pero estos hallazgos permiten concluir que los RCS en general, son menores en zonas de doble propósito comparadas con regiones con sistemas de producción de lechería especializada.

Comparando los datos de este estudio con los reportes nacionales, Piñeros et al., (2005), encontraron recuentos de 329.000 - $463.000 \mathrm{CS} / \mathrm{ml}$ en leche cruda del Alto Chicamocha (Boyacá) en sistemas de lechería especializada. Los resultados de este estudio fueron más altos (oscilaron entre 354.000 y $845.000 \mathrm{CS} / \mathrm{ml}$ ), lo que permite inferir que los programas de control de RCS y mastitis en promedio, están mejor en el Alto Chicamocha que en el promedio de las fincas analizadas en este estudio.

Comparando nuestros resultados con reportes internacionales, los estudios europeos reportan RCS en tanque que oscilan entre 100.000 y 251.000 Hillerton y Berry (2004); Østerås y Sølverød (2005); Berry et al., (2006), los canadienses entre 155.000 y 268.000 Sargeant et al., (1988); CDC (2008); Elmoslemany et al., (2009) y los estadounidenses entre 206.000 y 363.000 CS/ml Norman et al., (2000), Van Sheik et al., (2002); Jarayao et al., (2004), ver Tabla 7. Estos datos son muy inferiores a los reportados en este estudio, lo que presenta un reto en el desarrollo de planes de mejoramiento de la calidad sanitaria de leche para llegar a los niveles internacionales de RCS, principalmente en las zonas más afectadas. La proporción de leche 
Tabla 5. Calidad sanitaria de leche cruda en tanques y porcentaje del volumen que cumple estándares internacionales en 11 regiones colombianas.

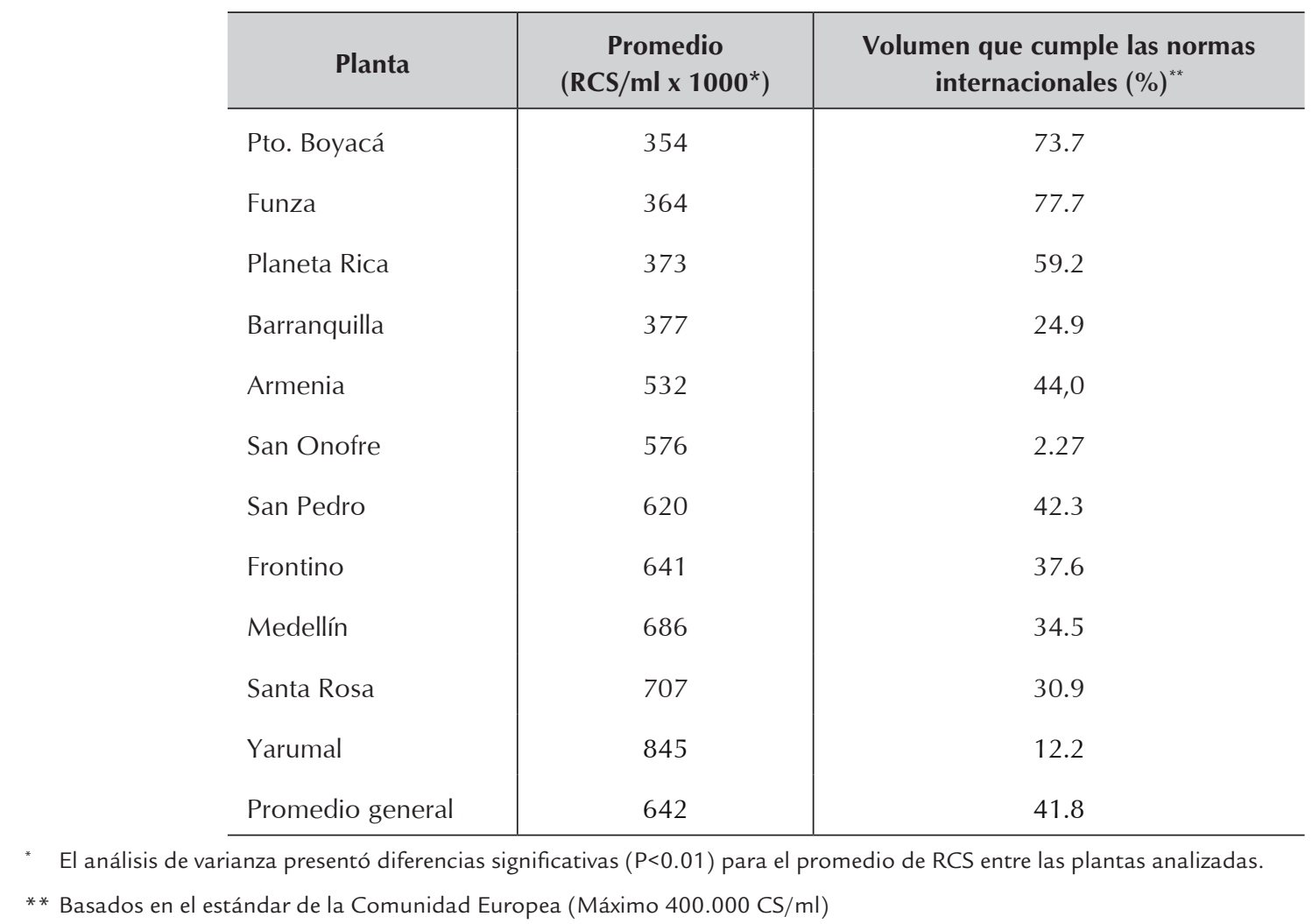

que cumple con las normas internacionales (medido en porcentaje de leche por debajo de $400.000 \mathrm{CS} / \mathrm{ml}$ ) osciló entre 2.27 y $77.72 \%$ según la planta (Tabla 5). El $11.03 \%$ de la leche captada se encuentra en un nivel excelente de RCS (menor de $200.000 \mathrm{CS} / \mathrm{ml}$ ), además encontró que un $41.82 \%$ de la leche cumple con el estándar europeo (menor de $400.000 \mathrm{CS} / \mathrm{ml}$ ) y poco menos del $76.76 \%$ de la leche del estudio cumpliría con el estándar de Estados Unidos (menor de 750.000 $\mathrm{CS} / \mathrm{ml}$, ver Tabla 6). Estos resultados contrastan con lo reportado en el Norte de Europa, donde más del 99\% de los productores cumplen con niveles de células somáticas por debajo de $400.000 \mathrm{CS} / \mathrm{ml}$. (Hillerton y Berry (2004)); en Canadá el 91.3\% (Elmoslemany et al., (2009)) y en Estados Unidos entre el 58.63 y el $88 \%$, dependiendo del estudio (Norman et al., (2000); Van Sheik et al., (2002); Jarayao et al., (2004)). Para el estándar estadounidense de $750.000 \mathrm{CS} / \mathrm{ml}$, el 96\% de la leche analizada cumplió con este nivel de calidad en ese país (Norman et al., (2000)). Bajo las actuales condiciones, más del $23 \%$ de la leche analizada excedería los máximos permitidos de RCS en Estados Unidos y más del $58 \%$ de la leche excedería los límites de la Unión Europea para este parámetro.
La Figura 1, ilustra la estacionalidad de las UFC y los RCS. El análisis estadístico estableció que no hay efecto del mes sobre el las UFC ni las RCS. Esto coincide con los resultados reportados por Pantoja et al., (2009), quienes concluyeron que los recuentos de UFC en leche cruda no fueron influidos por factores estacionales, sino más bien por efectos individuales inherentes a cada finca, y contradice otros estudios realizados en Estados Unidos y Canadá donde han encontrado que tanto RCS como UFC tienden a ser menores en invierno, y mayores en verano, Van Sheik et al., (2002); en un estudio en Estados Unidos encontraron que los RCS fueron menores entre octubre y enero $(280.000$ a $300.000 \mathrm{CS} / \mathrm{ml}$ ), comparados con los de Julio y Agosto (340.000 CS/ml).

Algunos trabajos han encontrado asociaciones entre el RCS y las UFC. Pantoja et al., (2009) en Wisconsin encontraron que las UFC del tanque se incrementaban $2.4 \%$ por cada $10.000 \mathrm{CS} / \mathrm{ml}$, mientras que Van Sheik et al., (2002) encontraron que fincas con alto RCS tienen tendencia a tener alto recuento de UFC. Este tipo de relación no se encontró en el promedio general de los datos del presente trabajo. El valor de $r^{2}$ fue de 0.43 
Tabla 6. Calidad sanitaria de la leche cruda discriminada por rangos durante 2010

\begin{tabular}{l|c|c}
\hline \multicolumn{1}{c|}{ Rangos de RCS } & Litros & Volumen (\%) \\
\hline Menos de 200.000 & 77.814 .320 & 11.0 \\
$200.001-400.000$ & 217.144 .112 & 30.8 \\
$400.001-600.000$ & 143.955 .048 & 20.4 \\
$600.001-800.000$ & 102.434 .301 & 14.5 \\
$800.001-1.000 .000$ & 70.636 .550 & 10.0 \\
$1.000 .001-1.200 .000$ & 40.869 .137 & 5.8 \\
$1.200 .001-1.400 .000$ & 22.522 .638 & 3.19 \\
$1.400 .001-1.600 .000$ & 12.830 .245 & 1.82 \\
$1.600 .001-1.800 .000$ & 6.984 .686 & 0.99 \\
$1.800 .001-2.000 .000$ & 3.628 .508 & 0.51 \\
Mayor a 2.000.001 & 6.390 .618 & 0.91 \\
\hline Total & 705.210 .165 & 100 \\
\hline
\end{tabular}

Tabla 7. Estudios previos de calidad higiénica y sanitaria en diferentes regiones del mundo

\begin{tabular}{|c|c|c|c|}
\hline País & Tipo de calidad & Valor reportado & Bibliografía \\
\hline $\begin{array}{l}\text { Colombia } \\
\text { Sabana de Bogotá } \\
\text { Alto Chicamocha }\end{array}$ & $\begin{array}{l}\text { Higiénica } \\
\text { Higiénica } \\
\text { Sanitaria }\end{array}$ & $\begin{array}{l}1.179 .000 \mathrm{UFC} / \mathrm{ml} \\
175.000-307.000 \mathrm{UFC} / \mathrm{ml} \\
329.000-463.000 \mathrm{CS} / \mathrm{ml}\end{array}$ & $\begin{array}{l}\text { Calderón et al., } 2006 \\
\text { Piñeros et al., } 2005\end{array}$ \\
\hline $\begin{array}{l}\text { Alemania, Holanda, } \\
\text { Suecia y Reino Unido }\end{array}$ & Sanitaria & $<200.000 \mathrm{CS} / \mathrm{ml}$ & Hillerton y Berry 2004 \\
\hline Austria & Sanitaria & 100.000 CS/ml & Hillerton y Berry 2004 \\
\hline $\begin{array}{l}\text { Canadá } \\
\text { Ontario } \\
\text { Todo el País } \\
\text { Isla Prince Edward }\end{array}$ & $\begin{array}{l}\text { Sanitaria } \\
\text { Sanitaria } \\
\text { Higiénica } \\
\text { Sanitaria }\end{array}$ & $\begin{array}{l}261.000 \mathrm{CS} / \mathrm{ml} \\
155.000-268.000 \mathrm{CS} / \mathrm{ml} \\
12.800 \mathrm{UFC} / \mathrm{ml} \\
218.000 \mathrm{CS} / \mathrm{ml}\end{array}$ & $\begin{array}{l}\text { Sargeant et al., } 1988 \\
\text { CDC } 2008 \\
\text { Elmoslemany et al., } 2009\end{array}$ \\
\hline $\begin{array}{l}\text { Estados Unidos } \\
\text { Todo el país } \\
\text { Nueva York }\end{array}$ & $\begin{array}{l}\text { Sanitaria } \\
\text { Higiénica } \\
\text { Higiénica } \\
\text { Sanitaria }\end{array}$ & $\begin{array}{l}313.500 \mathrm{CS} / \mathrm{ml} \\
11.400 \mathrm{UFC} / \mathrm{ml} \\
24.400 \mathrm{UFC} / \mathrm{ml} \\
363.000 \mathrm{CS} / \mathrm{ml}\end{array}$ & $\begin{array}{l}\text { Norman et al., } 2000 \\
\text { Peeler et al., } 1989 \\
\text { Van Sheik et al., } 2002\end{array}$ \\
\hline Pennsylvania & $\begin{array}{l}\text { Higiénica } \\
\text { Sanitaria }\end{array}$ & $\begin{array}{l}4.320 \text { UFC/ml } \\
315.190 \mathrm{CS} / \mathrm{ml}\end{array}$ & Jarayao et al., 2004 \\
\hline Wisconsin & $\begin{array}{l}\text { Higiénica } \\
\text { Sanitaria }\end{array}$ & $\begin{array}{l}12.500 \mathrm{UFC} / \mathrm{ml} \\
206.400 \mathrm{CS} / \mathrm{ml}\end{array}$ & Pantoja et al., 2009 \\
\hline Irlanda & Sanitaria & $251.000 \mathrm{CS} / \mathrm{ml}$ & Berry et al., 2006 \\
\hline Noruega & Sanitaria & $115.000 \mathrm{CS} / \mathrm{ml}$ & Østerås y Sølverød 2005 \\
\hline
\end{tabular}


con un valor de $\mathrm{p}<0.01$ lo que indica que los niveles de RCS explican el comportamiento de las UFC sólo en un $43.1 \%$, el resto se debe a otros factores.

El promedio general de RCS fue de $642.000 \mathrm{CS} / \mathrm{ml}$. Eberhart et al., citados por Philpot y Nickerson (2000) encontraron que los RCS en tanque con $500.000 \mathrm{CS} /$ $\mathrm{ml}$ se asociaban a un $16 \%$ de cuartos infectados y un $6 \%$ de pérdidas en producción de leche. El mismo estudio encontró que RCS en tanque de 600.000 CS/ $\mathrm{ml}$ presentaban entre un 61 y $79 \%$ de vacas infectadas con mastitis subclínica. Estos datos dimensionan el reto en desarrollar una cultura de prevención y control de mastitis en el país con el ánimo de ser competitivos en los mercados internacionales.

\section{Referencias}

Barbano DM, Ma Y, Santos MV. 2006. Influence of raw milk quality on fluid milk shelf life. Journal of Dairy Science, 89 (Suplemento): E15- E19. [05-12-2001] URL: http://download.journals.elsevierhealth.com/pdfs/journals/0022-0302/ PIIS0022030206723608.pdf

Berry DP, O'Brien B, O'Callaghan EJ, Sullivan KO, Meaney WJ. 2006. Temporal trends in bulk tank somatic cell count and total bacterial count in Irish dairy herds during the past decade. Journal of Dairy Science. 89: 4083-4093. [05-12-2011] URL: http://www. sciencedirect.com/science/article/pii/S0022030206724535

Boor KJ, Brpwn DP, Murphy SC, Kozlowski SM, Bandler DK. 1998. Microbiological and chemical quality of raw milk in New York state. Journal of Dairy Science. 81: 1743-1748. [05-122011] URL: http://www.sciencedirect.com/science/article/pii/ S002203029875742X

Calderón A, García F, Martínez G. 2006. Indicadores de calidad de leches crudas en diferentes regiones de Colombia. Rev. MVZ Córdoba. 11: 725-737. [05-12-2011] URL: http://dialnet.unirioja.es/servlet/articulo?codigo $=3299611$

CDC-Canadian Dairy Commission. 2006. Somatic cell and bacteria count. [05-12-2011] URL: http://www.dairyinfo.gc.ca/pdf/ count06.pdf

Elmoslemany AM, Keefe GP, Dohoo IR, Dingwell RT. 2009. Microbiological quality of bulk tank raw milk in Prince Edward Island dairy herds. Journal of Dairy Science. 92: 4239-4248. [05-122011] URL: http://www.sciencedirect.com/science/article/pii/ S0022030209707490

Ferraro D. 2006. Concepto de calidad de leche: su importancia para la calidad del producto final y para la salud del consumidor. Seminario Internacional de la calidad de la leche y prevención (Memorias). Consejo Nacional de la Calidad de la Leche y Prevención de la Mastitis CNLM.

FDA-Food and Drug Administration Grade "A". 2007. Pasteurized Milk Ordinance 2007 Revision. USA. Department of Health and Human Services. Public Health Service.

Hillerton JE, Berry EA. 2004. Quality of the milk supply: European regulations versus practice. NMC Annual Meeting Procee- dings. [05-12-2011] URL: http://www.nmconline.org/articles/ qualityeuro.pdf

Jayarao BM, Pillai SR, Sawant AA, Wolfgang DR, Hegde NV. 2004. Guidelines for monitoring bulk tank milk somatic cell and bacterial counts. Journal of Dairy Science. 87: 3561-3573. [05-122011] URL: http://www.sciencedirect.com/science/article/pii/ S0022030204734931

Jayarao BM, Donaldson SC, Straley BA, Sawant AA, Hegde NV, Brown JL. 2006. A survey of foodborne pathogens in bulk tank milk and raw milk consumption among farm families in Pennsylvania. Journal of Dairy Science. 89: 2451-2458. [05-122011] URL: http://www.sciencedirect.com/science/article/pii/ S0022030206723189.

Ma Y, Ryan C, Barbano DM, Galton DM, Rudan MA, Boor KJ. 2000. Effects of somatic cell count on quality and shelflife of pasteurized fluid milk. Journal of Dairy Science. 83: 264-274. [05-122011] URL: http://www.sciencedirect.com/science/article/pii/ S0022030200748739

McLaughlin F. 2006. A brief comparison of United States and European Union standards for fluid dairy production. Michigan State University. [29-04-2011] URL: http://www.iflr.msu.edu/ BookStudentPapers_files/A_Brief_Comparison_of_United_States_and_European_Union_Standards_for_Fluid_Dairy_Products.pdf

Ministerio de Agricultura. 2012. Resolución 017 de 2012. [4-92012] URL: http://www.minagricultura.gov.co/archivos/resolucion_17_2012.pdf

Ministerio de la Protección Social. 2006. Decreto número 616 de 2006. [29-04-2011] URL: http://www.sinigan.gov.co/portal/ portals/0/2006/d616.pdf

Norman HD, Miller RH, Wright JR, Wiggans GR. 2000. Herd and state means for somatic cell count from dairy herd improvement. Journal of Dairy Science. 83: 2782-2788. [05-12-2011] URL: http://www. sciencedirect.com/science/article/pii/S0022030200751757

Østerås O, Sølverød L. 2005. Mastitis control systems: The Norwegian experience. En: Proc. 4th Int. Dairy Fed. Int. Mast. ed. Wageningen Netherlands. p. 91-101

Pantoja JCF, Reinemann DJ, Ruegg PL. 2009. Associations among milk quality indicators in raw bulk milk. Journal of Dairy Science. 92: 4978-4987. [05-12-2011] URL: http://www.sciencedirect. com/science/article/pii/S002203020970829X

Peeler TJ, Messer JW, Sanders RL, Bachelor HK. A comparison of preliminary incubation counts and standard plate counts of Grade A bulk tank milk from eleven states. Dairy Food Environ. Sanit. 1989; 9: 494-497.

Philpot N, Nickerson S. 2000. Ganando la lucha contra la mastitis. Westfalia surge inc. Illinois, $192 \mathrm{p}$.

Piñeros G, Téllez G, Cubillos A. 2005. La calidad como factor de Competitividad en la cadena láctea Caso: cuenca lechera del alto Chicamocha (Boyacá). Universidad Nacional de Colombia, Bogotá. [05-04-2011] URL: http://www.veterinaria.unal.edu. co/inv/gipep/libro\%20calidad\%20leche.pdf

Posada S, Loaiza ET, Restrepo JE, Olivera M. 2010. Caracterización del ordeño manual e identificación de puntos críticos de con- 
trol para la calidad higiénica de la leche en una finca del norte de Antioquia. Revista Lasallista de Investigación. 7(2): 36-46. [05-12-2011] URL: http://www.lasallista.edu.co/fxcul/media/ pdf/Revista/vol7n2/35-46.pdf

Reyes J, Villar D, Olivera M. 2010. Evaluación de residuos de antimicrobianos por la prueba Delvotest ${ }^{\circledR}$ en una cuenca lechera de Antioquia con alto índice de mastitis subclínica. Revista Electrónica de Veterinaria (REDVET). 11(12): 1695-7504. [0512-2011] URL: http://www.veterinaria.org/revistas/redvet/ n121210/121009.pdf

Sargeant JM, Schukken YH, Leslie KE. 1998. Ontario bulk milk somatic cell count reduction program: progress and outlook. Journal of
Dairy Science. 81: 1545-1554. [05-12-2011] URL: http://www. sciencedirect.com/science/article/pii/S0022030298757200

Suárez R, Bazzani A. 2010. Coyuntura de la leche en Colombia Balance del año 2009. ANALAC. Área de estudios económicos. [05-12-2011] URL: http://establo.info/Documentos/COYUNTURA\%20DE\%20LA\%20LECHE\%20EN\%20COLOMBIA\%20 Mz29.pdf

Van Schaik G, Lotem M, Schukken YH. 2002. Trends in somatic cell counts, bacterial counts, and antibiotic residue violations in New York state during 1999-2000. Journal of Dairy Science. 85: 782-789. [05-12-2011] URL: http://www.sciencedirect. com/science/article/pii/S0022030202741362 